\title{
ANÁLISE DE UMA ATIVIDADE EXPERIMENTAL SOBRE BIOGÁS A PARTIR DE ELEMENTOS DA TEORIA DA ASSIMILAÇÃO DAS AÇÕES MENTAIS
}

\author{
ANALYSIS OF AN EXPERIMENTAL ACTIVITY ON BIOGAS FROM ELEMENTS OF \\ THE THEORY OF ASSIMILATION OF MENTAL ACTIONS
}

\author{
Leandro Cesar Santos Silva ${ }^{1}$, Verônica Tavares Santos Batinga²
}

Recebido: janeiro/2020 Aprovado: abril/2021

\begin{abstract}
Resumo: Esse trabalho analisa o percurso de assimilação de conhecimentos pelos licenciandos de química durante a resolução de questões acerca dos conceitos de metano e reações químicas envolvidos na produção de Biogás a partir da realização de uma atividade experimental. 0 experimento foi aplicado a estudantes na disciplina de Ensino de Química de uma Instituição de Ensino Superior de Pernambuco, Brasil. A análise dos dados foi feita a partir de aspectos da teoria da assimilação das ações por etapas de Galperin, em particular, buscando identificar a forma e a qualidade das ações realizadas pelos sujeitos no processo de formação de conceitos científicos. Galperin apresenta categorias relativas à forma e a qualidade das ações realizadas. As ações são parte da atividade e devem orientar o aluno para alcançar o objetivo de aprendizagem. Os resultados indicam que os licenciandos realizaram a ação de diferentes formas, e mostram níveis diferenciados de assimilação dos conceitos químicos trabalhados na resolução de questões, que foram evidenciados por meio das categorias graus de generalização, detalhamento e consciência. É possível considerar que a forma da ação realizada pelos estudantes no plano material (externo) vai sendo internalizada de modo gradativo e/ou integrado para o plano da ação mental.
\end{abstract}

Palavras-chave: experimentação, aprendizagem, ensino de química, teoria de Galperin.

\begin{abstract}
This work analyzes the course of assimilation of knowledge by the chemistry graduates during the resolution of questions about the concepts of methane and chemical reactions involved in the production of Biogas from the realization of an experimental activity. The experiment was applied to students in the Chemistry Teaching discipline of a Higher Education Institution in Pernambuco, Brazil. The analysis of the data was made from aspects of Galperin's assimilation theory of actions in stages, in particular, seeking to identify the form and quality of the actions performed by the subjects in the process of forming scientific concepts. Galperin presents categories related to the form and quality of the actions carried out. Actions are part of the activity and should guide the student to achieve the learning objective. The results indicate that the undergraduates carried out the action in different ways, and show different levels of assimilation of the chemical concepts worked in the resolution of issues, which were evidenced through the categories degrees of generalization, detailing and awareness. It is possible to consider that the form of action performed by students on the material (external) plane is gradually being internalized and / or integrated into the mental action plane.
\end{abstract}

Keywords: experimentation, learning, chemistry teaching, Galperin's theory.

https://orcid.org/0000-0003-1039-3920 - Mestre em Ensino das Ciências pela Universidade Federal Rural de Pernambuco (UFRPE). Mentor da Gulbenkian Aprendizagem (GAP), Moita, CEP: 2835-220, Setúbal, Portugal. E-mail: ufrpe.mestrado@gmail.com

2 (iD https://orcid.org/0000-0002-9660-396X - Doutora em Educação pela Universidade Federal de Pernambuco (UFPE). Profa. do PPGEC e PROFQUI da Universidade Federal Rural de Pernambuco (UFRPE), Recife, Pernambuco, Brasil. Rua Dom Manuel de Medeiros, s/n, Dois Irmão, CEP: 52171-900, Recife, Pernambuco, Brasil. E-mail:veratsb@gmail.com 


\section{Introdução}

Pesquisas na área de Didática de Ciências têm apresentado crescente produção científica na investigação sobre Ensino de Química, sobretudo para estratégias e abordagens de ensino, o papel da linguagem na construção de conceitos científicos e modelos de formação docente (SCHNETZLER, 2002). No entanto, Carvalho e Gil-Pérez (2011) salientam acerca da incipiente inclusão dessas estratégias e abordagens nos cursos de formação inicial de professores, especificamente, a abordagem de Resolução de Problemas (RP). Isso justifica a necessidade de pesquisas sobre esta abordagem no processo de ensino e aprendizagem de futuros professores de química no sentido de propiciar a contextualização de conhecimentos químicos e contribuir para a vivência de estratégias de ensino diferenciadas.

Freire e Silva (2013) destacam que como parte da formação inicial é importante que professores de Química vivenciem a abordagem de RP com objetivo de construir um conhecimento profissional fundamentado, e que possa estimulá-los a propor problemas em suas aulas no exercício da futura profissão. A abordagem de RP propicia o aluno vivenciar processos de observação, reflexão, ação e investigação, favorecendo uma percepção de que o conhecimento científico é construído a partir de processos situados culturalmente, e a ciência é compreendida como uma atividade humana, dinâmica e aberta (BATINGA e TEIXEIRA, 2014).

A RP articulada a atividades experimentais favorece a contextualização de conceitos de química e a integração com temas sóciocientíficos para a discussão das relações entre Ciência, Tecnologia, Sociedade e Ambiente (BATINGA e TEIXEIRA, 2014; ). Nesse trabalho tais abordagens foram contempladas em sala de aula a partir do desenvolvimento de uma Sequência de Ensino e Aprendizagem (SEA).

Segundo Amaral e Ferreira (2018), a elaboração, aplicação e análise de propostas de intervenção em sala de aula, delineadas a partir de SEA e estruturadas com atividades que fazem uso de recursos didáticos diversos têm sido uma forma de articular aspectos teóricos e práticos nas investigações e propostas didáticas para o ensino de química. A SEA pode ser planejada para abordar temas multidisciplinares, sóciocientíficos e problemas relacionados a vários conteúdos curriculares.

Para delimitar o tema e os conteúdos da SEA foi realizado um levantamento bibliográfico a fim de identificar pesquisas na área de ensino de química que discutam a RP como uma abordagem de ensino e aprendizagem, usando as palavras-chaves: química, ensino superior de química, licenciatura em química e RP. O levantamento foi feito em 10 periódicos Revista Electrónica de Enseñanza de las Ciencias, Educacion Quimica, Química Nova, Formación Universitária, Research in Science \& Technological Education, Revista Electrónica de Investigación Educativa, Enseñanza de las Ciencias, Estudios Pedagógicos, Tecné, episteme y didaxis e Revista Brasileira de Ensino de Ciência e Tecnologia (nacionais e internacionais) da área de ensino de Ciências classificadas no Qualis A e B pela Coordenação de Pessoal de Nível Superior (CAPES) no período de 2008 a 2017.

O critério de escolha dos periódicos ocorreu devido à disponibilidade de artigos na versão digital na internet e por contemplar pesquisas que tratam da formação de professores e ensino de ciências e química. Por meio da leitura e análise dos títulos, resumos e textos dos artigos 
foram encontrados 16 artigos sobre a abordagem de RP. Dentre eles, 8 pesquisas foram realizadas com estudantes do curso de Licenciatura em Química. A análise destas pesquisas mostrou que os conceitos de metano e reações químicas, e o tema Biogás não foram abordados nas pesquisas encontradas. Nesse trabalho, o levantamento contribuiu para delimitação do tema e dos conceitos estudados para a elaboração da SEA com base na RP. A SEA consta de diversas atividades, dentre elas, uma atividade experimental sobre a produção de Biogás associada à resolução de questões sobre conceitos químicos abordados nesta atividade, a qual será objeto de análise dessa pesquisa.

Nesse contexto, esse trabalho objetiva analisar o percurso de assimilação de conhecimentos pelos licenciandos de química durante a resolução de questões acerca dos conceitos de metano e reações químicas envolvidos nas etapas de produção de Biogás, simulada a partir de uma atividade experimental. Para tanto, a análise das respostas dos licenciandos as questões sobre a atividade experimental foi realizada a partir de aspectos da teoria da assimilação das ações por etapas de Galperin (1986), em particular, buscando-se identificar nas respostas a forma e a qualidade das ações realizadas pelos licenciandos no processo de formação de conceitos de metano e reação química na produção de Biogás.

\section{Abordagem de Resolução de Problemas (RP)}

A RP é uma abordagem de ensino centrada no aluno e se caracteriza pelo uso de problemas como ponto de partida para uma aprendizagem contextual de conceitos científicos na educação básica e ensino superior (LEITE e ESTEVES, 2006).

Segundo Leite e Afonso (2001) resolver problemas é uma atividade muito frequente nas aulas de ciências e química nos diferentes níveis educacionais, que possibilita a assimilação de conhecimento científico escolar e acadêmico para resolver problemas e tomar decisões que envolvem aspectos científicos. Daí a importância de professores em formação inicial vivenciarem a RP em disciplinas de ensino de Química.

As características da conceituação de problema apresentadas por Batinga e Teixeira (2014) foram adotadas nesse trabalho: uma situação real ou fictícia que o indivíduo ou grupo precisa resolver, entretanto, não possui uma resposta imediata que leve à solução. Nesse sentido, um problema requer dos sujeitos que buscam resolvê-lo processos de reflexão, elaboração de hipóteses e estratégias a serem seguidas durante sua resolução.

A RP se aproxima da perspectiva histórico-cultural por considerar a mediação da linguagem, dos instrumentos e recursos e da interação sujeito-objeto e sujeito-sujeito no processo de formação de conceitos. Nessa abordagem o professor atua como mediador da resolução de problemas contextualizados, e os alunos participam ativamente desse processo. Dentre as características metodológicas da RP, Vasconcelos e Almeida (2012) destacam: 1) apresentação de problema real ou fictício; 2) identificação das necessidades de aprendizagem do aluno; 3) utilização de atividades e recursos didáticos que motivem o aluno para a resolução do problema; 4) comunicação do que foi assimilado a partir do problema e 5) avaliação da aprendizagem. 
Para o desenvolvimento da RP na sala de aula foi elaborada e aplicada uma SEA sobre Biogás para analisar o percurso de assimilação de conceitos científicos pelos licenciandos de química. Segundo Méheut e Psillos (2004), as SEA são sequências de aulas e atividades articuladas tendo seu design representado por duas dimensões interativas. A primeira refere-se à conexão entre o mundo real e o conhecimento científico a ser ensinado (dimensão epistêmica) e a segunda trata da interação entre professor e alunos e alunos-alunos (dimensão pedagógica).

Nesse trabalho buscamos integrar as dimensões epistêmicas e pedagógicas no design da SEA, enfatizando a relevância do conteúdo a ser ensinado, sua gênese histórica, as características cognitivas dos alunos e a motivação para a aprendizagem (MÉHEUT, 2005). Os resultados das ações e atividades realizadas pelos licenciandos no desenvolvimento da SEA foram utilizados para analisar o percurso de aprendizagem.

\section{Aspectos das Teorias da Atividade de Leontiev e da Assimilação das Ações por Etapas de Galperin}

A teoria histórico-cultural segundo Leontiev e Galperin traz contribuições para a aprendizagem no sentido de entendê-la como um processo contextual e interativo, que é resultado da participação dos alunos em uma comunidade. Nesse processo, o professor atua como mediador, participando junto com os alunos e oferecendo vários tipos de ajuda, como: i) construir pontes no nível de compreensão e habilidades iniciais dos alunos para outros níveis mais complexos; ii) estruturar a participação dos alunos, apresentando a atividade de forma dinâmica, adequando-se às condições do contexto e iii) transferir gradualmente o controle das atividades até que o aluno consiga realiza-las de forma independente (GALPERIN, 1986).

Para Leontiev (1985), a atividade é um processo no qual o aluno age ativamente sobre a realidade e conceitos a assimilar. Seus elementos são: sujeito e objeto da atividade, motivos, ações, objetivo, sistema de operações, meios, condições e resultados/produtos. As ações são parte da atividade e orientam o aluno a alcançar o objetivo de aprendizagem. As operações são procedimentos por meio dos quais a ação se realiza.

Galperin elaborou um método de construção sistemática de ações mentais, voltado paras as atividades de ensino e aprendizagem, e organizado para revelar as etapas necessárias que as ações mentais sofrem em sua gênese, uma vez que se originam de ações materiais, passando por uma série de etapas até a formação da ação mental (TALíZINA, 1988). Para esse autor, a assimilação da ação ou sua apropriação em habilidade para a formação de conceitos científicos não se produz só pela ação informativa do professor, mas pelas etapas que levam a ação orientadora do plano externo ao plano mental. Galperin (1986) estabelece três processos associados entre si que são a orientação, execução e controle.

1) Orientação: refere-se às orientações que possibilitam tipos específicos de assimilação da ação. Por exemplo, a forma em que se realiza a ação é a medida do grau de interiorização da ação, a qual pode ser realizada de formas diferentes: a) no plano material: utilizando os meios (objetos, materiais e instrumentos) para realizar a ação ou no plano materializado quando se utiliza esquemas, diagramas ou modelos que expressam relações essenciais entre os componentes do objeto de assimilação; b) no plano da linguagem externa, quando os alunos 
utilizam a linguagem verbal (escrita e oral) e c) no plano mental quando a ação se cumpre na forma mental percorrendo o caminho da interiorização, transformando-se de ação externa para interna (GALPERIN, 1986).

2) Execução: refere-se às etapas da assimilação da ação, descritas a seguir:

- Etapa motivacional: visa o engajamento dos alunos no processo de ensino e aprendizagem. Esse primeiro passo destina-se a fornecer os requisitos iniciais, a fim de estimular a motivação e mantê-la durante o processo de aprendizado. Os conteúdos de aprendizagem devem ser apresentados de forma significativa, desde o início do processo de ensino, partindo, por exemplo, da RP para aumentar o engajamento do aluno no decorrer das atividades (NÚNEZ e PACHECO, 1997);

- Base orientadora da ação (BOA): são estruturadas ações para estabelecimento de condições concretas para a sua realização.

- Plano material ou materializado: os alunos atuam em objetos materiais (objetos reais) ou sua representação (modelos, desenhos, diagramas, figuras e esquemas). Na Etapa de formação da ação no Plano/ (Forma Material ou Materializado) os alunos começam a executar as ações em parceria com os colegas, buscando transferir as ações (generalização) para resolver novas atividades (SILVA, 2011). Este processo ocorre simultaneamente com a linguagem, que ajuda na reflexão sobre o objeto de estudo ou sua representação. Segundo Talízina (1988), a atividade em grupo é necessária para a formação da atividade individual, uma vez que Vygotsky aponta que as funções psicológicas superiores são formadas a partir de formas coletivas da atividade. Nessa pesquisa envolvendo a SEA sobre Biogás, o trabalho em grupo é destaque na abordagem de RP por contemplar duas componentes importantes no processo de aprendizagem, a cognitiva/acadêmica e a social/interpessoal (VASCONCELOS e ALMEIDA, 2012).

- Plano da linguagem externa: os elementos da ação são expressos em palavras, por meio da linguagem externa verbal (oral ou escrita). Na etapa de formação da ação no plano da Linguagem Externa, a linguagem assume um papel fundamental por permitir a criação de signos que adquirem significados e passam a ser interiorizados pelos sujeitos de forma independente da presença do objeto de estudo (NÚÑEZ e PACHECO, 1997). Do ponto de vista da RP, a realização de ações favorece a interação entre alunos-professor, alunos-alunos e alunosespecialistas no processo educativo (VASCONCELOS e ALMEIDA, 2012; SILVA, 2011). Então, essa etapa acontece em sala de aula quando há interações ocorridas entre os sujeitos, no intuito de esclarecer e sistematizar resultados das ações desenvolvidas pelos alunos. Nesse estudo, ações de discussão sobre a resolução de questões de uma atividade experimental, debates e explicações elaboradas de forma oral são exemplos de como a Linguagem Externa pode estar presente nas atividades de uma SEA sobre Biogás baseada na RP.

- Plano mental: a ação se cumpre na forma mental ("na mente"), transformando uma ação externa em interna. Essa etapa possibilita o trabalho independente do estudante. Destacase que tais etapas não ocorrem de forma linear, entretanto, podem ser separadas metodologicamente para fins de análise. 
3) Controle: Visa regular o processo de assimilação a partir da avaliação da qualidade da ação pelos parâmetros qualitativos: graus de generalização, percepção/detalhamento, consciência e independência

O grau de generalização relaciona-se com a extensão do conceito e o limite de aplicação da ação. A generalização é máxima quando se aplica o conceito e a ação em situações possíveis. É deficiente quando se aplica o conceito e a ação em situações não aplicáveis. O grau de percepção/detalhamento refere-se ao nível de detalhamento da ação em seus componentes. No processo de assimilação de novas ações na formação de conceitos, a ação inicial deve realizar-se de forma desdobrada para que o sujeito tenha consciência dos componentes que a integram, só depois é que se inicia o processo de síntese da ação até chegar à forma reduzida, que corresponde à forma mental (Galperin, 1986).

O grau de consciência refere-se à possibilidade de realizar a ação corretamente e de fundamentar sua realização na forma verbal. Esse grau refere-se ao conhecimento procedimental das habilidades que um sujeito domina, as quais são demonstradas a partir da ação. Exemplo: quando o aluno se dá conta do que está fazendo e o porquê da ação, então ele utiliza a linguagem verbal para traduzir a lógica da ação para a lógica dos conceitos. Isso demostra uma ação consciente por parte do sujeito. O grau de independência consiste na possibilidade do aluno realizar corretamente uma ação, com ou sem certos níveis de ajuda/mediação. Este tende a aumentar à medida que os alunos avançam nas etapas de assimilação do processo de formação de conceitos na atividade de aprendizagem (NUÑEZ e PACHECO, 1997).

Segundo a teoria de Galperin (1986), a formação de conceitos e habilidades se desenvolve pela atividade e comunicação do estudante, e a partir da condição em que se realiza certos tipos de ações estruturadas em etapas. Esse autor afirma que o desenvolvimento das etapas deve estar orientado para a definição e aplicação do conceito a ser assimilado, visto que contribui para a formação de generalizações e abstrações (SILVA, 2011). Nesse contexto, busca-se responder a seguinte questão de pesquisa: Quais formas e qualidades das ações emergem no processo de assimilação dos conceitos de metano e reações químicas pelos licenciandos em química na atividade experimental sobre a produção de Biogás, que considera finalidades citadas por Wesendonk e Terrazzan (2020).

\section{Metodologia}

Essa pesquisa é de caráter qualitativo envolvendo um estudo de caso porque busca a compreensão de fenômenos no contexto em que ocorre e do qual faz parte (YIN, 2005). Em particular, nesse trabalho, o fenômeno relaciona-se com o percurso de assimilação de conceitos químicos realizado pelos licenciados de química matriculados em uma disciplina de Ensino de química de uma Instituição de Ensino Superior (IES). Os procedimentos metodológicos adotados para o desenvolvimento da pesquisa foram: 1) Elaboração da sequência, 2) Desenvolvimento da sequência e 3) Análise da Sequência.

Na elaboração da SEA sobre Biogás (GRAHAN SOLOMONS, 2004; KARLSSON, 2014) foram contempladas as dimensões epistêmica e pedagógica (MÉHEUT e PSILLOS, 2004) e considerados 
elementos da abordagem de RP, tais como: apresentação de um problema, recursos/atividades motivadores para discussão e resolução do problema, trabalho colaborativo, e avaliação do processo de aprendizagem (VASCONCELOS e ALMEIDA, 2012). O problema denominado de P1 é apresentado no quadro 1.

Quadro 1 - Problema P1

Sabe-se que o aumento das concentrações de gases como $\mathrm{CO}_{2}, \mathrm{CH}_{4}$ e $\mathrm{N}_{2} \mathrm{O}$ na atmosfera é um dos fatores responsáveis pelo agravamento do efeito estufa. Alternativas para a redução destes gases estão sendo utilizadas tanto na cidade quanto no campo, por meio da produção de Biogás. Nesse contexto, solicitamos que você descreva as etapas do processo de obtenção de Biogás. Questionamento 1: Qual seria a matéria-prima utilizada nesse processo? Questionamento 2: Há formação de novas substâncias, nesse processo? Se sim, explique utilizando a linguagem/representação química. Questionamento 3: Qual a tecnologia envolvida na obtenção de Biogás?

Fonte: Elaborado pelos autores (2020)

A SEA sobre Biogás foi desenvolvida no âmbito da formação inicial de professores de química, no curso de Licenciatura em Química de uma IES de Pernambuco. Participaram da pesquisa dez estudantes, durante um total de 10 aulas geminadas de 60 minutos cada. As aulas foram divididas em 5 momentos: 1: Apresentação e resolução de P1, 2: Atividade Experimental envolvendo a produção de Biogás, 3: Aula Expositiva Dialogada e Resolução de questões sobre o experimento, 4: Visita de campo a um laboratório de pesquisa de Biogás e 5: Elaboração de Produção Textual.

Para atender o objetivo da pesquisa que busca analisar formas e qualidades das ações que emergem no processo de assimilação dos conceitos de metano e reações químicas pelos licenciandos de química na realização da atividade experimental sobre a produção de Biogás, recortamos e descrevemos os momentos 1 a 3 ( 6 aulas geminadas de 60 minutos cada) que constituem atividades da SEA. No momento 1 , os alunos responderam individualmente 0 problema P1 (Quadro 1), que objetiva identificar suas concepções sobre metano, reações químicas e principais tecnologias envolvidas na produção de biogás. No momento 2 , os alunos organizados em grupos trouxeram diferentes resíduos orgânicos de alimentos: arroz, sementes de feijão, macarrão e casca de banana para realizar um experimento, que simulou a tecnologia e etapas envolvidas na produção de biogás e integram os conceitos de metano e reações químicas ocorridas na fase metanogênica. $O$ professor leu o roteiro experimental com as orientações sobre a montagem do biodigestor (experimento) e solicitou aos alunos a resolução de questões sobre o experimento. Estas foram respondidas pelos licenciandos e socializadas com a turma no momento 3 . Esta atividade visa à mobilização de conceitos abordados no P1, com base nas contribuições da atividade experimental e da aula expositiva dialogada (momento 3).

No momento 3, a aula abordou aspectos históricos do biogás; metano: conceito, representação química, ocorrência e reações ocorridas na etapa da digestão anaeróbia (metanogênese); tecnologia, condições e parâmetros para obtenção de biogás; aspectos sociais, 
político-econômicos e ambientais relacionados à produção de Biogás. No decorrer da aula o professor apresentou aos licenciandos, por meio de slides, os diferentes tipos de biodigestores (chinês e indiano), os estudos desenvolvidos no Brasil sobre biogás, as fases da digestão anaeróbica com ênfase na metanogênica, a relação entre hidrocarbonetos e biocombustíveis e os principais alcanos, sua representação e estrutura (metano, propano e butano). O quadro 2 descreve as atividades, objetivos, ações, objeto e resultados/produtos esperados no desenvolvimento da SEA para os momentos 1, 2 e 3, com base em categorias de Leontiev (1985):

Quadro 2 - Aspectos da teoria de Leontiev considerados na elaboração da SEA.

\begin{tabular}{|c|c|c|c|c|}
\hline Atividades & Objetivos & $\begin{array}{l}\text { Ações dos } \\
\text { alunos }\end{array}$ & Objeto/conteúdos & Produto/Resultado \\
\hline $\begin{array}{l}\text { Resolução do } \\
\text { Problemas P1 }\end{array}$ & $\begin{array}{l}\text { Identificar } \\
\text { concepções dos } \\
\text { licenciandos } \\
\text { sobre conteúdos } \\
\text { químicos } \\
\text { associados à } \\
\text { produção de } \\
\text { Biogás }\end{array}$ & $\begin{array}{l}\text { Utilizar } \\
\text { estratégias } \\
\text { mobilizar } \\
\text { conhecimentos } \\
\text { prévios para } \\
\text { resolver } \\
\text { problema }\end{array}$ & $\begin{array}{l}\text { matéria-prima, } \\
\text { tecnologia e reações } \\
\text { químicas na } \\
\text { produção do biogás }\end{array}$ & $\begin{array}{l}\text { Respostas Iniciais ao } \\
\text { Problema P1 }\end{array}$ \\
\hline $\begin{array}{l}\text { Atividade } \\
\text { Experimental e } \\
\text { Resolução de } \\
\text { questões sobre } \\
\text { o experimento }\end{array}$ & $\begin{array}{l}\text { Mobilizar } \\
\text { conceitos } \\
\text { envolvidos no } \\
\text { problema a } \\
\text { partir do } \\
\text { experimento e } \\
\text { aula expositiva } \\
\text { dialogada }\end{array}$ & $\begin{array}{l}\text { Realizar a } \\
\text { montagem de } \\
\text { um biodigestor } \\
\text { Responder } \\
\text { questões sobre o } \\
\text { experimento }\end{array}$ & $\begin{array}{l}\text { Metano, reações } \\
\text { químicas ocorridas } \\
\text { na produção de } \\
\text { biogás e Tecnologia } \\
\text { de Biodigestores }\end{array}$ & 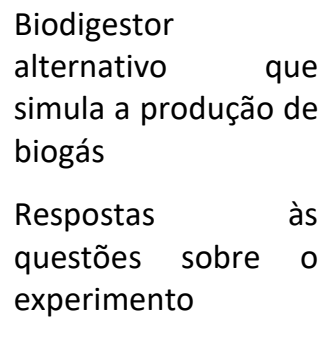 \\
\hline
\end{tabular}

Fonte: Elaborado pelos autores (2020)

Os dados obtidos a partir do desenvolvimento da SEA foram analisados com base nas categorias de orientação, execução e controle, segundo Galperin (1986), em particular, buscando identificar e analisar as formas e a qualidade das ações realizadas pelos licenciandos no processo de assimilação de conceitos científicos. Esse artigo centra-se, especificamente, na análise das respostas dos licenciandos na atividade de resolução de questões sobre conceitos químicos abordados a partir da atividade experimental, envolvendo a produção de Biogás e da aula expositiva dialogada (Momentos 2 e 3). Os conceitos trabalhados nas quatro questões foram: definição, composição, representação geométrica, função química do principal composto do Biogás (metano), etapas e reações químicas relacionadas com a produção desse combustível renovável.

As respostas dos licenciandos foram categorizadas de acordo com os parâmetros qualitativos da ação realizada (quadro 3) e com as formas das ações (Galperin, 1986) (quadro 4) no processo de assimilação dos conceitos trabalhados. 
Quadro 3 - Níveis/Graus dos Parâmetros Qualitativos da Ação do sujeito.

\begin{tabular}{|c|c|c|c|}
\hline $\begin{array}{l}\text { Parâmetros } \\
\text { Qualitativos }\end{array}$ & $\begin{array}{l}\text { Grau insuficiente } \\
\text { (não desenvolvido) }\end{array}$ & $\begin{array}{l}\text { Grau Regular } \\
\text { (pouco desenvolvido) }\end{array}$ & $\begin{array}{l}\text { Grau Bom } \\
\text { (muito desenvolvido) }\end{array}$ \\
\hline Generalização & $\begin{array}{l}\text { O aluno não identifica a } \\
\text { composição química do } \\
\text { biogás, não reconhece as } \\
\text { reações e não especifica } \\
\text { funções orgânicas } \\
\text { envolvidas no processo. } \\
\text { Não é capaz de explicar o } \\
\text { funcionamento de um } \\
\text { biodigestor e não } \\
\text { compreende os fatores } \\
\text { que influenciam a } \\
\text { produção de metano }\end{array}$ & $\begin{array}{l}\text { O aluno identifica em parte } \\
\text { a composição química do } \\
\text { biogás, além de nem } \\
\text { sempre reconhecer as } \\
\text { reações e especificar as } \\
\text { funções orgânicas } \\
\text { envolvidas no processo. } \\
\text { Nem sempre é capaz de } \\
\text { explicar o funcionamento } \\
\text { de um biodigestor e, } \\
\text { algumas vezes, não } \\
\text { compreende os fatores que } \\
\text { influenciam a produção de } \\
\text { metano }\end{array}$ & $\begin{array}{l}\text { O aluno identifica a } \\
\text { composição química do } \\
\text { biogás, reconhece as } \\
\text { reações e específica } \\
\text { funções orgânicas } \\
\text { envolvidas no processo. } \\
\text { É capaz de explicar o } \\
\text { funcionamento de um } \\
\text { biodigestor e } \\
\text { compreende os fatores } \\
\text { que influenciam a } \\
\text { produção de metano }\end{array}$ \\
\hline Consciência & $\begin{array}{l}\text { Não é capaz de realizar a } \\
\text { ação e explicar } \\
\text { verbalmente o que está } \\
\text { fazendo }\end{array}$ & $\begin{array}{l}\text { É, em parte, capaz de } \\
\text { realizar a ação e explicar } \\
\text { verbalmente o que está } \\
\text { fazendo }\end{array}$ & $\begin{array}{l}\text { É capaz de realizar a ação } \\
\text { e explicar verbalmente o } \\
\text { que está fazendo }\end{array}$ \\
\hline Independência & $\begin{array}{l}\text { Não consegue realizar a } \\
\text { ação sem ajuda do } \\
\text { professor ou de qualquer } \\
\text { outra pessoa }\end{array}$ & $\begin{array}{l}\text { Consegue, em parte, } \\
\text { realizar a ação sem ajuda do } \\
\text { professor ou de qualquer } \\
\text { outra pessoa }\end{array}$ & $\begin{array}{l}\text { O aluno consegue } \\
\text { realizar a ação sem ajuda } \\
\text { do professor ou de } \\
\text { qualquer outra pessoa }\end{array}$ \\
\hline
\end{tabular}

Fonte: Elaborado pelos autores com base em GALPERIN (1986) e NÚNEZ e PACHECO (1997)

Quadro 4 - Formas que o sujeito realiza a ação.

\begin{tabular}{|l|l|l|l|}
\hline \multicolumn{3}{|c|}{ Formas da Ação } \\
\hline Plano Material & Plano Materializado & Plano da Linguagem Externa & Plano Mental \\
\hline
\end{tabular}

Fonte: Elaborado pelos autores com base em Galperin (1986)

\section{Resultados e Discussão}

A etapa motivacional foi contemplada na resolução do problema P1 e nos demais momentos. Os alunos realizaram ações no plano material quando executaram procedimentos de montagem do biodigestor alternativo de produção de Biogás (representação material). A elaboração de respostas acerca das questões sobre o experimento corresponde à etapa de 
formação da ação no plano materializado e da linguagem externa, expressa na forma verbal (oral e escrita) pelos alunos, que concorda com etapa de assimilação das ações segundo Galperin (1986). A resolução de questões pelos licenciandos possibilitou a assimilação dos conceitos de metano e reações envolvidos na atividade experimental, que se relacionam com o questionamento 2 do problema P1: Há formação de novas substâncias nesse processo? Se sim, explique utilizando a linguagem/representação química.

Tanto a atividade experimental quanto a resolução das quatro questões foram realizadas em 4 grupos, denominados de: G1 (AD1, AE, AJ), G2 (AN, AF, AD2), G3 (AM, AL) e G4 (AC, AT). A Q1 objetiva identificar a composição química do Biogás, utilizando a representação/linguagem cientifica adequada. A Q2 tem como objetivo compreender aspectos químicos relativos ao principal composto $\left(\mathrm{CH}_{4}\right)$ que constitui o Biogás. Já, a Q3 requer a representação das etapas de produção de Biogás. E a Q4 objetiva identificar a etapa de formação do Biogás e representar as reações envolvidas nesse processo. No quadro 5, apresentamos uma síntese da análise da Resolução de Questões pelos licenciandos sobre o Experimento.

Quadro 5 - Síntese da análise da Resolução de Questões sobre o Experimento.

\begin{tabular}{|c|c|c|c|}
\hline Questões & Grupos & $\begin{array}{l}\text { Parâmetros } \\
\text { Qualitativos }\end{array}$ & Nível \\
\hline $\begin{array}{l}\text { Q1 Descreva a composição } \\
\text { do Biogás, utilizando a } \\
\text { linguagem química. }\end{array}$ & $\begin{array}{l}\mathrm{G} 1 \\
\mathrm{G} 3 \\
\mathrm{G} 4 \\
\mathrm{G} 2\end{array}$ & $\begin{array}{l}\text { Consciência/ } \\
\text { Detalhamento } \\
\text { Consciência/ } \\
\text { Detalhamento }\end{array}$ & $\begin{array}{l}\text { Bom/Bom } \\
\text { Insuficiente/Insufici } \\
\text { ente }\end{array}$ \\
\hline $\begin{array}{l}\text { Q2 Para o Biogás: defina, } \\
\text { represente sua estrutura } \\
\text { geométrica, e identifique a } \\
\text { que função química ele } \\
\text { pertence. }\end{array}$ & $\begin{array}{l}\mathrm{G} 1 \\
\mathrm{G} 2 \\
\mathrm{G} 3 \\
\mathrm{G} 4\end{array}$ & $\begin{array}{l}\text { Generalização } \\
\text { /Consciência }\end{array}$ & Regular/Regular \\
\hline $\begin{array}{l}\text { Q3 Faça um desenho que } \\
\text { represente as principais } \\
\text { etapas de obtenção de } \\
\text { Biogás, desde a entrada de } \\
\text { resíduos orgânicos até a } \\
\text { utilização do produto } \\
\text { obtido. }\end{array}$ & $\begin{array}{l}\text { G1 } \\
\text { G2 } \\
\text { G3 } \\
\text { G4 }\end{array}$ & Generalização/Consciência & Bom /Bom \\
\hline $\begin{array}{l}\text { Q4 Em qual das etapas é } \\
\text { formado o biogás? } \\
\text { Represente quimicamente } \\
\text { as reações envolvidas } \\
\text { nesse processo }\end{array}$ & $\begin{array}{l}\mathrm{G} 1 \\
\mathrm{G} 2 \\
\mathrm{G} 3 \\
\mathrm{G} 4\end{array}$ & $\begin{array}{l}\text { Consciência/Detalhamento } \\
\text { Consciência/ Detalhamento }\end{array}$ & $\begin{array}{l}\text { Regular/Regular } \\
\text { Bom/Bom }\end{array}$ \\
\hline
\end{tabular}

Fonte: Elaborado pelos autores (2020) 
A resposta do G1 a Q1 representa o desenvolvimento da ação realizada (responder a Q1) no plano da linguagem externa (palavras) por meio do registro escrito. Percebe-se que G1 realiza a ação de forma consciente, com base em Núñez e Pacheco (1997), uma vez que a resposta expressa está correta quanto à composição química do Biogás, e a linguagem apresentada (fórmulas químicas) corresponde à representação satisfatória usada na descrição das substâncias que constituem o Biogás. Apresentamos a resposta do G1:

G1: "A composição do biogás varia conforme o material a ser degradado e as condições químicas e físicas que influenciam no processo da biodigestão anaeróbia. Em média o biogás é composto pela seguinte proporção de gases: Metano $\left(\mathrm{CH}_{4}\right)$ : 55- 65\%; Gás Carbônico $\left(\mathrm{CO}_{2}\right)$ : 35 45\%; Nitrogênio $\left(\mathrm{N}_{2}\right)$ : 0 - 3\%; Hidrogênio $\left(\mathrm{H}_{2}\right)$, Oxigênio e Gás Sulfídrico: 0 - 1\%".

Os grupos G3 e G4 apresentaram respostas que apontam indícios de tomada de consciência (compreensão correta) do objeto (composição química do biogás) e de detalhamento, quando elencam os diferentes gases que constituem o Biogás. Esses dois grupos responderam além do que foi pedido na Q1, no que diz respeito à proporção de cada gás (G4) e de alguns fatores que influenciam as diferentes proporções de gases presentes no sistema de biodigestores (G3). Nessa direção percebe-se que o grau de consciência tem uma relação com o grau de detalhamento da ação, conforme destacado por Galperin (1986), porque os alunos identificaram e descreveram corretamente a ação em todos os seus componentes alcançando o objetivo da atividade (Quadro 2). Apresentamos as respostas de G3 e G4:

G3: "O biogás é composto de $\mathrm{CH}_{4}$ (Metano), $\mathrm{CO}_{2}$ (Dióxido de Carbono), $\mathrm{H}_{2} \mathrm{~S}$ (gás sulfídrico), $\mathrm{H}_{2} \mathrm{O}$ (água), $\mathrm{N}_{2}$ (Nitrogênio), $\mathrm{O}_{2}$ (Oxigênio), $\mathrm{H}_{2}$ (Hidrogênio), porém a proporção de cada um desses gases na mistura vai depender das bactérias presentes no sistema".

G4: "Composição do Biogás: $\mathrm{CH}_{4}$ variando entre $40 \%$ e $85 \%$; $\mathrm{CO}_{2}$ variando entre $20 \%$ e $35 \%$ outros gases variando entre $2 \%$ e $6 \%$ ".

O G2 afirma que o biogás é constituído apenas por metano $\left(\mathrm{CH}_{4}\right)$ sem levar em consideração outros gases que o compõem ( $\mathrm{G} 2$ : “ $\mathrm{CH}_{4}$ metano"). Essa resposta indica um grau de consciência e detalhamento insuficiente na qualidade das ações realizadas na atividade de resolução da Q1, e que estas foram formadas predominantemente no plano material, com base em Silva (2011). O grupo compreende as instruções do roteiro experimental da atividade, mas não realiza a ação de forma correta, fundamentada e detalhada.

Para a Q2, todos os grupos apresentaram respostas satisfatórias porque representaram quimicamente o composto principal presente no biogás, identificando sua função química e estrutura geométrica. Essa questão também trouxe a tona o plano materializado, de acordo com Silva (2011) , quando os alunos atuam no objeto de estudo (conceitos químicos), de modo a realizar a ação de representar a estrutura química (modelo) do metano, e de outros compostos envolvidos na produção do Biogás.

As respostas dos grupos indicam um grau de generalização de nível regular, pois conseguiram assimilar, em parte, os conceitos químicos abordados na Q2 do experimento. Quanto ao grau de consciência a resposta dos grupos indica um nível regular na realização da ação porque responderam de forma parcialmente satisfatória, com relação à definição do 
metano, por exemplo, o G3 e G4. Percebe-se na resolução dessa questão, que as ações externas realizadas pelos alunos se deslocam de forma tímida do plano material para o mental, que concorda com resultados de pesquisa de Souza e Batinga (2013). No quadro 6 apresentamos as respostas dos grupos 3 e 4 .

Quadro 6 - Respostas de G3 e G4 para Q2.

\begin{tabular}{|l|l|}
\hline G3 & $\begin{array}{l}\text { Biogás é um gás renovável que deriva da matéria orgânica, e que serve como recurso energético, } \\
\text { para aproveitar gases poluentes de resíduos. } \mathrm{CH}_{4} \text { : Metano, estrutura tetraédrica e apolar, gás } \\
\text { incolor, hidrocarboneto. } \mathrm{CO}_{2} \text {; Gás Carbônico, estrutura linear e apolar, gás incolor e inodoro, } \\
\text { molécula inorgânica. }\end{array}$ \\
\hline G4 & $\begin{array}{l}\mathrm{CH}_{4} \text { : hidrocarboneto, tetraedro. } \mathrm{CO}_{2} \text { : óxido, linear. } \mathrm{H}_{2} \mathrm{O} \text { : óxido, angular } \mathrm{H}_{2} \mathrm{~S} \text { : ácido angular } \mathrm{N}_{2} \text { : gás } \\
\text { nitrogênio, linear } \mathrm{O}_{2} \text { : gás oxigênio } \mathrm{H}_{2} \text { : gás hidrogênio linear. }\end{array}$ \\
\hline
\end{tabular}

Fonte: Elaborado pelos autores (2020)

As respostas de todos os grupos a Q3 foram satisfatórias, uma vez que representaram por meio de diagrama (plano materializado) e linguagem química descritiva as principais fases da digestão anaeróbia, com base no experimento realizado (plano material), que representam as formas da ação de acordo com Silva (2011) e Souza e Batinga (2013).

G1 elaborou um esquema com a descrição das principais etapas da digestão anaeróbia, que representa uma compreensão mais ampla da ação, que se situa no plano materializado e da linguagem externa verbal escrita, evidenciando os principais processos químicos e biológicos que ocorrem dentro do biodigestor. Por outro lado, G2 fez um esquema mais linear e sintético para representar a produção de Biogás, desde a entrada de amostra até a saída do biocombustível. As formas de ação predominantes são a materializada e do plano da linguagem externa escrita, de acordo com Silva (2011) e Núñez e Pacheco (1997). Apresentamos as respostas de G1 e G2 no Quadro 7.

Quadro 7 - Resposta de G1 e G2 a Q3

\begin{tabular}{|l|l|l|}
\hline F1 & Matéria $\longrightarrow$ Hidrólise $\longrightarrow$ Formação de Subprodutos \\
\hline G2 & $\begin{array}{l}\text { 1) preparação de amostra } \\
\text { obtenção de biogás amostra pronta 3) hidrólise e fermentação 4) metanogênese 5) }\end{array}$ \\
\hline
\end{tabular}

Fonte: Elaborado pelos autores (2020).

As representações expressas (quadro 7) apontam que os grupos realizaram ações que levou a assimilação da Q3 a partir da relação de conceitos químicos e biológicos envolvidos na 
produção do Biogás (metano), e da explicitação das etapas e reações que ocorrem no biodigestor por meio da articulação de ações no plano material e materializado (montagem do biodigestor) com o plano da linguagem externa (resolução das questões). Tais aspectos apontam para qualidades das ações no nível bom para os graus de generalização e consciência nas ações executadas pelos alunos, conforme quadro 3, baseado em Galperin (1986) e Núñez e Pacheco (1997).

$\mathrm{Na}$ Q4, dois grupos (G3 e G4) apresentaram respostas satisfatórias e 2 grupos (G1 e G2) parcialmente satisfatória. Os estudantes identificaram dentre as fases da biodigestão, a metanogênese como a etapa de formação de metano $\left(\mathrm{CH}_{4}\right)$ e representaram as reações químicas presentes nesta etapa. llustramos com a resposta de G3:

G3: "Na etapa da metanogênese é onde ocorre a formação do metano, principal produto do biogás, as reações a seguir mostram esse processo pela via do acetato e redução de $\mathrm{CO}_{2}$ : Metanogênese hidrogenotróficas: $\mathrm{H}_{2}+\mathrm{CO}_{2} \rightarrow \mathrm{CH}_{4}+\mathrm{H}_{2} \mathrm{O}$ e Metanogênese acetoclástica: $\mathrm{CH}_{3} \mathrm{COO}^{-} \rightarrow \mathrm{CH}_{4}+\mathrm{CO}_{2}^{\prime \prime}$.

Percebe-se na resposta de G3 que a qualidade das ações se situa no nível bom nível para os graus de consciência e detalhamento destas pelos alunos. Eles justificaram de forma correta, fundamentada e completa a representação química das reações envolvidas. Isso fica evidente quando expressam que o biogás também é formado pela redução do $\mathrm{CO}_{2}$ e do acetato. Essas respostas demonstram um nível satisfatório no processo de assimilação do conteúdo tratado nesta questão. Isso corrobora com Talízina (1988) quando afirma que a forma das ações no plano material deve se estabelecer de modo detalhado para que ao chegar à etapa mental se reduzam, automatizando as operações de forma consciente, e permitindo ao estudante agir com rapidez na resolução de atividades.

G1 e G2 se apresentaram respostas incompletas a Q4. Eles executaram a ação com predomínio da forma no plano materializado (G2) e da linguagem externa (G1), com base em Núñez e Pacheco (1997) e Silva (2011). Eles usaram termos gerais e simplificados tanto na explicação da etapa de formação de Biogás, quanto na representação da reação química ocorrida nesse processo. Isto aponta que a qualidade da ação relativa aos graus de consciência e detalhamento, realizada pelos dois grupos se situa no nível regular, baseado em Galperin (1986) e Núñez e Pacheco (1997).

G1: “A digestão anaeróbica pode ser definida como um ecossistema onde diversos grupos de microrganismos trabalham interativamente na conversão da matéria orgânica complexa nos gases presentes no Biogás".

G2: "Na etapa 4 da questão anterior, $\mathrm{MO}+$ bactérias $\rightarrow \mathrm{CH}_{4}(\mathrm{~g})+\mathrm{CO}_{2}(\mathrm{~g})+$ resíduo sólido orgânico.".

De um modo geral, os resultados corroboram com Galperin (1986), quando afirma que a ação inicialmente realizada pelo sujeito no plano material vai sendo internalizada de modo gradativo até ser executada no plano mental. 


\section{Considerações Finais}

Na resolução das questões (Q1, Q2, Q3 e Q4) sobre o experimento envolvendo a produção de Biogás, os licenciandos demostraram diferentes níveis de assimilação dos conceitos químicos abordados, que são evidenciados a partir de distintas formas e qualidades de realizar a ação, as quais emergiram na análise das respostas dos grupos. As formas das ações realizadas pelos grupos situam-se no plano material, materializado e da linguagem externa escrita e oral. Enquanto, a qualidade das ações executadas pelos grupos nesta atividade foi: graus de detalhamento, consciência e generalização. $O$ grau de independência não foi analisado em virtude de os licenciandos desenvolverem as atividades em grupos e com o auxílio do professor.

Pensar na formação de conceitos científicos a partir do desenvolvimento de uma SEA sobre Biogás é introduzir os estudantes na realização de atividades e ações colaborativas, fornecendo-lhes ferramentas cognitivas e culturais necessárias, orientando seu progresso no processo de assimilação para ações mentais. Esses são alguns aspectos da teoria de Galperin, que podem ser considerados na elaboração de atividades e experimentos de sequências voltadas para o ensino de ciências.

\section{Referências}

AMARAL, E.M.R.; FERREIRA, H.S. Análise e validação de sequência de ensino aprendizagem a partir de atividades e ações propostas. In: Isauro Béltran Núnez; Betânia Leite Ramalho. (Org.). Galperin e a teoria da formação planejada por etapas das ações mentais e dos conceitos. Campinas: 1ed. Mercado das Letras, 2018, v. 1, p. 1-424.

BATINGA, V. T. S.; TEIXEIRA, F. M. A Abordagem de Resolução de Problemas por uma professora de Química: análise de um problema sobre a Combustão do Álcool envolvendo o conteúdo de Estequiometria, R. B. E. C. T., v.7, n. 1, p. 24-52, 2014.

CARVALHO, A.M.P.; GIL-PÉREZ, D. Formação de Professores de Ciências: Tendências e Inovações. São Paulo: Cortez. 2011.

FREIRE, M.S.; SILVA, M.G.L. Como formular problemas a partir de exercícios? Argumentos dos licenciandos em Química. Revista Electrónica de Enseñanza de las Ciencias, v.12 (1). p.191-208. 2013. Disponível em: <http://reec.uvigo.es/REEC/spanish/REEC_older_es.htm>. Acesso: 20 de agosto de 2019.

GALPERIN, P.Y. Sobre el método de formación por etapas de las acciones intelectuales. Antología de la Psicología Pedagógica y de las edades. Havana. Editorial Pueblo y Educación. p.114-118. 1986.

GRAHAM SOLOMONS, T.W. Fundamentos de Química Orgánica. 2ed. Editorial Limusa S.A. 2004. $1215 p$.

KARLSSON, T. et al. Manual Básico de Biogás. Lajeado: Ed. da UNIVATES, 2014.

LEITE, L.; AFONSO, A.S. Aprendizagem Baseada na Resolução de Problemas: Características, Organização e Supervisão. Boletim das Ciências. v.48. p.253-260. 2001. 
LEITE, L.; ESTEVES, E. Trabalho em grupo e aprendizagem baseada na resolução de problemas: Um estudo com futuros professores de Física e de Química. In: Atas do Congresso Internacional, Lima (Perú): Pontificia Universidad Católica del Perú. 2006. Disponível em:< http://hdl.handle.net/1822/9986>. Acesso: 25 de setembro de 2019.

LEONTIEV, A.N. Actividad, Conciencia y Personalidad. La Habana Editorial. Pueblo y Educación, 1985.

MÉHEUT, M. Teaching-learning sequence tools for learning and/or research. In: BOERSMA, K. et.al. Research and Quality of Science Education. Holanda: Springer, 2005. Disponível em: <https://link.springer.com/chapter/10.1007/1-4020-3673-6_16>. Acesso: 04 de agosto de 2019.

MÉHEUT, M.; PSILLOS, D. Teaching-learning sequences aims and tools for science education research. International Journal of Science Education. v.26 (5). p.515-535. 2004. Disponível em: <https://www.tandfonline.com/doi/abs/10.1080/09500690310001614762>. Acesso: 05 de agosto de 2019.

NUÑEZ, I.B.; PACHECO, O.G. La formación de conceptos científicos: una perspectiva desde la teoría de la actividad. Natal: EDUFRN, 1997. p. 139.

SCHNETZLER, R.P. A Pesquisa em Ensino de Química no Brasil: Conquistas e Perspectivas.

Química Nova. v.25. p.14-24. 2002. Disponível em: <http://quimicanova.sbq.org.br/detalhe_artigo.asp?id=5258> Acesso: 22 de setembro de 2019.

SILVA, P.B. Desenvolvimento e avaliação de uma abordagem de ensino de química centrada na curiosidade científica dos estudantes e elaborada com base na teoria da formação das ações mentais por etapas de Galperin. 2011, 293 f. Tese (Educação) Universidade Federal de Pernambuco. Recife.

SOUZA, J.S.A.; BATINGA, V.T.S. Validação de uma sequência didática de química a partir de aspectos da teoria da atividade de Leontiev e da teoria da assimilação por etapas dos conceitos e ações de Galperin. Revista Amazônica, v. 16, n. 2, p. 342-368, 2013.

TALÍZINA, N.F. Psicología de la enseñanza. Moscou: Progreso, 1988.

VASCONCELOS, C.; ALMEIDA, A. Aprendizagem Baseada na Resolução de Problemas no Ensino das Ciências: Propostas de Trabalho para Ciências Naturais, Biologia e Geografia. Porto, Portugal: Porto Editora. 2012.

WESENDONK, F.S.; TERRAZZAN, E.A. Condições acadêmico-profissionais para a utilização de experimentações por professores de física do ensino médio. Ensino de Ciências e Tecnologia em Revista, v.10, n.1, p. 39-55, 2020.

YIN, R.K. Estudo de Caso: Planejamento e Métodos. 3ed. Porto Alegre: Bookman, 2005 